\title{
Efficacy of Topical Blockade of Interleukin-1 in Experimental Dry Eye Disease
}

\section{Citation}

Okanobo, Andre, Sunil K. Chauhan, Mohammad H. Dastjerdi, Shilpa Kodati, and Reza Dana. 2012. "Efficacy of Topical Blockade of Interleukin-1 in Experimental Dry Eye Disease." American Journal of Ophthalmology 154 (1) (July): 63-71. doi:10.1016/j.ajo.2012.01.034.

\section{Published Version}

10.1016/j.ajo.2012.01.034

\section{Permanent link}

http://nrs.harvard.edu/urn-3:HUL.InstRepos:34428278

\section{Terms of Use}

This article was downloaded from Harvard University's DASH repository, and is made available under the terms and conditions applicable to Other Posted Material, as set forth at http:// nrs.harvard.edu/urn-3:HUL.InstRepos:dash.current.terms-of-use\#LAA

\section{Share Your Story}

The Harvard community has made this article openly available.

Please share how this access benefits you. Submit a story.

Accessibility 


\title{
Efficacy of topical blockade of interleukin-1 in experimental dry eye disease
}

\author{
Andre Okanobo, Sunil K. Chauhan, Mohammad Dastjerdi, Shilpa Kodati, and Reza Dana \\ Schepens Eye Research Institute and Massachusetts Eye and Ear Infirmary, Harvard Medical \\ School, Boston, MA, USA
}

\begin{abstract}
PURPOSE-To evaluate the therapeutic efficacy of topical IL-1Ra in the treatment of Dry Eye Disease (DED).

DESIGN—Laboratory Investigation.

METHODS-DED was induced in C57BL/6 female mice through exposure to a desiccating environment within a controlled environment chamber. Topical formulations containing $5 \%$ IL-1Ra, $1 \%$ methylprednisolone, $0.05 \%$ cyclosporin A (CsA), and a vehicle control containing carboxymethylcellulose sodium (CMC) were applied following the induction of dry eye. Corneal fluorescein staining (CFS) was performed by a masked observer in the different treatment groups. Immunohistochemical studies were undertaken to enumerate corneal CD11b+ cells, as well as to evaluate corneal lymphangiogenesis. Real-time polymerase reaction was used to quantify the expression of IL- $1 \beta$ in the cornea.

RESULTS-A significant decrease in CFS was observed following topical treatment with 5\% IL-1Ra $(\mathrm{P}<0.01), 1 \%$ methylprednisolone $(\mathrm{P}<0.01)$, and $0.05 \%$ CsA $(\mathrm{P}<0.03)$. Additionally, a significant decrease in the numbers of central corneal CD11b+ cells $(\mathrm{P}<0.05)$, corneal lymphatic growth $(\mathrm{P}<0.05)$, and corneal IL-1 $\beta$ expression $(\mathrm{P}<0.003)$, compared to vehicle treated, were only demonstrated following treatment with 5\% IL-1Ra and $1 \%$ methylprednisolone, and were absent following CsA treatment.
\end{abstract}

CONCLUSIONS-Topical treatment with IL-1Ra is efficacious in ameliorating the clinical signs of the DED, as well as in reducing underlying inflammation.These effects are comparab le to

\footnotetext{
(C) 2012 Elsevier Inc. All rights reserved.

Corresponding Author: Reza Dana, MD, MSc, MPH, Schepens Eye Research Institute, 20 Staniford Street, Boston MA 02114, Telephone: 617-912-7404; Fax: 617-912-0117, reza.dana@ schepens.harvard.edu.

Financial Disclosures:

The Schepens Eye Research Institute has filed for intellectual property rights for the use of IL-1 blockade in the treatment of ocular diseases. S.K.C., M.D., and R.D. are co-inventors of a patent application licensed by their institution to Eleven Biotherapeutics Inc, Cambridge, MA. R.D. holds equity position at Eleven Biotherapeutics Inc.

Contributions to Authors in each of these areas:

Design of the study (S.K.C., R.D.); Conduct of the study (A.O., M.D.); Collection (A.O., M.D.); Management (S.K.C., R.D.); Analysis and interpretation of Data (A.O., S.K.C., S.K.); preparation of manuscript (S.K.C., A.O., S.K.); review or approval of manuscript (S.K.C., S.K., R.D.).
}

Statement about Conformity with Author Information:

The research protocol was approved by the Schepens Eye Research Institute Animal Care and Use Committee, and it conformed to the standards in the Association for Research in Vision and Ophthalmology Statement for the Use of Animals in Ophthalmic and Vision Research.

Publisher's Disclaimer: This is a PDF file of an unedited manuscript that has been accepted for publication. As a service to our customers we are providing this early version of the manuscript. The manuscript will undergo copyediting, typesetting, and review of the resulting proof before it is published in its final citable form. Please note that during the production process errors may be discovered which could affect the content, and all legal disclaimers that apply to the journal pertain. 
treatment with topical methylprednisolone. Topical IL-1Ra may hold promise as a novel therapeutic strategy in the treatment of dry eye.

\section{INTRODUCTION}

Dry eye disease (DED) is an extremely common ocular disorder, and large epidemiological studies, using a variety of definitions, have estimated its prevalence to approximate 10-20\% of the adult population. ${ }^{1}$ DED is defined as a multifactorial condition of the tears and ocular surface, characterized by symptoms of discomfort, visual disturbance and tear film instability with potential damage to the ocular surface. Moreover, it is accompanied by increased osmolarity of the tear film and inflammation of the ocular surface. ${ }^{1}$ DED can affect visual function, and thus common tasks of daily living such as reading, speed and driving are adversely affected by this condition. ${ }^{2}$

Inflammation has been recognized as an important component of DED and antiinflammatory therapies have therefore proven useful in decreasing ocular surface inflammation, stimulating tear production, and improving the overall signs and symptoms of dry eye. ${ }^{3}$ Moreover, consistent with the concept that inflammation is a key feature in the pathophysiology of DED is the finding that the clinical signs and symptoms of dry eye improve with methylprednisolone and cyclosporin (CsA). ${ }^{4,} 5$ Unfortunately the long-term use of topical corticosteroids is limited by potential sight-threatening side effects, such as glaucoma, cataract and infection. ${ }^{6}$ Furthermore, CsA, the only drug approved by the FDA in the United States for treatment of DED, is associated in some patients with burning and stinging sensation, and requires several months to produce a clinical therapeutic effect. ${ }^{7}$

Interleukin-1 receptor antagonist (IL-1Ra) is an endogenous IL-1 receptor antagonist, which is primarily produced by activated monocytes and tissue macrophages, and inhibits the activities of the proinflammatory forms of IL-1 (IL-1 $\alpha$ and IL-1 $\beta$ ) by competitively binding to the IL-1 receptor-I (IL-1RI). ${ }^{8} \mathrm{IL}-1 \mathrm{Ra}$ is typically upregulated in inflammatory conditions, such as in rheumatoid arthritis to down-modulate the inflammatory functions of the IL-1RI ligation by the agonistic ligands, IL- $1 \alpha$ and IL- $1 \beta .{ }^{9}$ Although, the binding affinity of natural IL-1Ra to its receptor is similar to that of IL-1a/IL-1 $\beta$, higher concentrations of IL-1Ra relative to agonistic IL-1 ligands have been shown to be required to completely inhibit the cellular effects of IL-1. ${ }^{10,11}$ This is probably due to the fact that only $5 \%$ receptor availability for IL-1 can initiate inflammatory responses and thus virtually all cellular IL-1RI receptors must be blocked for sufficient suppression of the IL-1 system. ${ }^{11,12}$ Normal tear fluid has been found to contain high concentrations of IL-1Ra in concentrations 25,000 and 40,000 times greater than both proinflammatory forms of IL- $1,{ }^{13}$ and it is thought that concentration of IL-1Ra in the tear fluid may therefore be a natural homeostatic mechanism for regulation of IL-1-mediated functions on the ocular surface. ${ }^{14}$

Given the critical role of inflammation in the pathogenesis of DED ${ }^{15}$, we examined the therapeutic efficacy of topical IL-1Ra in DED using a validated murine model of dry eye ${ }^{16}$. Our data shows a significant amelioration of clinical signs of DED in IL-1Ra treated mice. In addition, we investigated the effect of topical IL-1Ra in modulating infiltration of inflammatory cells, expression of inflammatory cytokine and lymphangiogenesis in dry eye cornea - mechanisms that are of pathophysiologic relevance in DED induction and progression ${ }^{17,18}$ - and demonstrate significant suppression of DED-associated inflammation with topical use of IL-1Ra. 


\section{METHODS}

Animals

Eight to ten week old female C57BL/6 mice (Charles River Laboratory, Wilmington, MA) were used in this study.

\section{Induction of Dry Eye}

Dry eye was induced in the mice by placing them in a Controlled Environment Chamber (CEC), which allows continuous regulation of relative humidity below $30 \%$, a constant temperature of $21-23^{\circ} \mathrm{C}$ and airflow of $15 \mathrm{~L} /$ minute, 24 hours a day. ${ }^{16}$ To achieve maximum ocular surface dryness, the conditions in CEC were supplemented with topical application of $1 \%$ atropine sulfate (Falcon Pharma, Fort Worth, Texas) twice daily for the first 48 hours. Additionally, the mice also received on their dorsal surface subcutaneous injections $0.1 \mathrm{ml}$ $(5 \mathrm{mg} / \mathrm{ml})$ of scopolamine hydrobromide (Sigma-Aldrich, St. Louis, MO) to exacerbate dry eye three times a day (9 AM, 1 PM, 5 PM) for the entire duration of the experiment.

\section{Topical Formulations and Treatment Regimen}

The formulations tested included 5\% IL-1Ra, $1 \%$ methylprednisolone, $0.05 \%$ Cyclosporin A (Restasis, Allergan, Irvine, CA). The topical IL-1Ra and methylprednisolone were formulated aseptically from the commercially available intravenous Anakinra (Kineret, Biovitrum, Stockholm, Sweden) and methylprednisolone sodium succinate respectively, and transferred into a sterile, light-protected dropper container. Anakinra $(50 \mathrm{mg} / \mathrm{ml})$ was diluted in carboxymethylcellulose sodium (Refresh Liquigel, Allergan, Irvine, CA) and methylprednisolone $(10 \mathrm{mg} / \mathrm{ml})$ was diluted in nonpreserved sterile normal saline solution. Forty-eight hours after the induction of dry eye, the mice in the CEC were randomly divided into five different groups ( $\mathrm{n}=8-10$ in each group): (i) an untreated group, (ii) a group receiving topical vehicle control (carboxymethylcellulose sodium), (iii) a group receiving $5 \% \mathrm{IL}-1 \mathrm{Ra}$, (iv) a group receiving $0.05 \% \mathrm{CsA}$ and (v) a group receiving $1 \%$ methylprednisolone. Three microliters of the eye drop were applied topically to both eyes of unanesthetized mice three times a day from 48 hours to day 9 (total 21 doses). The untreated group received no eye drops. Ocular signs of dry eye were evaluated using fluorescein staining at day 2, day 6 and day 9. Mice were then euthanized on day 10 for cellular and molecular studies.

\section{Corneal Fluorescein Staining}

Fluorescein staining of the corneal epithelium was used as a diagnostic tool to study the effect of desiccating stress on the ocular surface of the mice. Corneal fluorescein staining was performed at baseline (day 0, before placing the mice in the CEC), day 2 (before instillation of topical therapy), day 6 and finally at day $9.0 .7 \mu \mathrm{L}$ of $2.5 \%$ fluorescein (Sigma-Aldrich, St. Louis, MO) was applied to the eye using a micropipette into the inferior conjunctival sac ( $\mathrm{n}=8$ eyes per group) as previously described. ${ }^{16}$ After three minutes, punctate staining on the corneal surface was evaluated in a maskedfashion using a slit lamp biomicroscope under cobalt blue light. The National Eye Institute grading system was used to assess the corneal surface staining. ${ }^{19,20}$

\section{RNA Isolation and Molecular analysis using Real Time Polymerase Chain Reaction}

Total RNA was isolated from the cornea tissues using the RNeasy microkit (Qiagen, Valencia, CA; catalog No. 74004). Two corneas per group were isolated, pooled together and stored at $-80^{\circ} \mathrm{C}$ in Trizol (Invitrogen, Carlsbad, California; catalog No. 15596026) until future use. The first strand of cDNA was synthesized with random hexamers using SuperScriptTM III Reverse Trancriptase (Invitrogen, Carlsbad, CA; catalog No.18080) 
according to the manufacturer's recommendations, and utilizing 500ng of total RNA. RealTime PCR was performed using FAM-MGB dye labeled predesigned primers (Applied Biosystem, Foster City, CA) for GAPDH (assay ID.Mm99999915_g1), IL-1 $\beta$ (assay ID.Mm00434228_m1). Two and half $\mu \mathrm{L}$ of cDNA was loaded in each well and assays were performed in duplicates. A non-template control was included in all the experiments to evaluate DNA contamination of the reagent used. The GAPDH gene was used as the endogenous reference for each reaction. The results were normalized by the cycle threshold (CT) of GAPDH and the relative mRNA level in the untreated group was used as the normalized control for the others groups.

\section{Immunohistochemical Staining}

The following primary antibodies were used for immunohistochemical staining: rat antimouse CD11b-FITC for monocytes/macrophages (BD Pharmingen, San Diego, California, 1:100), goat anti-mouse CD31 FITC as pan-endothelial marker (Santa Cruz Biotechnology, Santa Cruz, California, 1:100) and purified rabbit anti-mouse LYVE-1 as lymphatic endothelial marker (Abcam, MA, USA, 1:400). Respective isotypes were used as negative controls. The secondary antibody used was Rhodamine conjugated goat anti-rabbit (BD Pharmingen, San Diego, California, 1:100). For whole mount immunofluorescence corneal staining, freshly excised corneas were washed in PBS and acetone fixed for 15 minutes and then stained with CD11b or double stained with CD31 and LYVE-1 as described previously. ${ }^{21}$ To analyze infiltration of $\mathrm{CD}_{11} \mathrm{~b}^{+}$cells, corneas from three mice from each group were taken and cells were counted in 6 areas in the periphery $(0.5 \mu \mathrm{m}$ area from the limbus) and the center (central $2 \mu \mathrm{m}$ area) of the cornea in a masked fashion, using confocal microscope (Leica TCS 4D; Lasertechnik, Heidelberg, Germany) at 40X magnification (Figure 2A). The mean number of cells was obtained by averaging the total number of cells in all the areas studied and the result was expressed as the number of positive cells per $\mathrm{mm}^{2}$.

\section{Quantification of Corneal Lymphangiogenesis}

The lymphatics were analyzed by an automated image analysis program using Matlab (The Mathworks, Inc., Natick, MA). ${ }^{22}$ Lymphatics were isolated from 12 digitized immunofluorescent micrographs with this program, and subsequently analyzed the Lymphatic Area (LA). LA represents the total surface area of the lymphatic vessels when projected into the plane of the image.

\section{Statistical Analysis}

A two-tailed Student's t-test was performed and $P$-values less than 0.05 were deemed statistically significant. Results are presented as the mean \pm standard error of the mean (SEM) of at least three experiments.

\section{RESULTS}

\section{Amelioration of clinical signs of dry eye}

The clinical signs of dry eye were measured by corneal fluorescein staining using the National Eye Institute grading scheme. On day 0, mice were placed in the CEC and after 48 hours all mice showed an increase in corneal staining corresponding to dry eye induction (Fig 1A). Topical treatment with the 5\% IL-1Ra, 1\% methylprednisolone, $0.05 \%$ CsA and the vehicle control (CMC) were started on day 2 and corneal fluorescein staining scores were measured at days 6 and 9. Treatment with topical 5\% IL1-Ra, $1 \%$ methylprednisolone and $0.05 \% \mathrm{CsA}$ led to a significant decrease in corneal fluorescein staining compared to the untreated and vehicle group at day $6(P<0.01)$ and day $9(P<0.003)$ (Fig $1 \mathrm{~A})$. Moreover, $5 \%$ IL-1Ra and $1 \%$ methylprednisolone showed a statistically significant greater reduction 
in the CFS score compared to $0.05 \%$ CsA at day $9(55 \%$ and $60 \%$ vs. $34 \%$; respectively; $P<$ 0.01) (Fig 1B).

\section{Reduction of CD11b+ cells infiltration in dry eye cornea}

The normal cornea has a resident population of bone marrow-derived immature CD11 $\mathrm{b}^{+}$ antigen-presenting cells ${ }^{23}$, and the induction of dry eye is associated with a significant increase in the number of corneal CD11 $\mathrm{b}^{+}$cells ${ }^{24}$. Using confocal microscopy of corneal whole mounts, we investigated $\mathrm{CD} 11 \mathrm{~b}^{+}$cells infiltrating the cornea of different regimen treated groups (Fig 2A). A significant decrease was seen in the number of CD11b+cells, both in the periphery and the center, of dry eye corneas which were treated with $5 \% \mathrm{IL}-1 \mathrm{Ra}$ $(176.2 \pm 6.5$ and $125.0 \pm 3.4)$ and $1 \%$ methylprednisolone $(176.1 \pm 5.4$ and $132.1 \pm 3.5)$ compared to vehicle treated dry eye corneas $(260.7 \pm 11.0$ and $164 \pm 7.1)$ (Fig 2B). However, $0.05 \%$ CsA treated group only showed a significant decrease in the number of $\mathrm{CD}_{11} \mathrm{~b}^{+}$cells in the peripheral corneas compared to vehicle treated corneas $(209.5 \pm 6.8 \mathrm{vs}$. $260.7 \pm 11.0 ; P=0.004)$ (Fig 2B). No difference in the CD11b+ cell numbers was observed between untreated and vehicle treated dry eye corneas.

\section{Reduction in the expression of IL-1 $\beta$ in dry eye cornea}

DED is accompanied by an increase in the proinflammatory forms of IL- $1 .{ }^{13}$ Therefore, to determine the relative efficacy of the different treatment regimens on the gene expression of IL- $1 \beta$, real-time PCR was performed to quantify the transcript expression of IL- $1 \beta$ in the cornea of different groups ( $\mathrm{n}=4$ to 6 per group). Analysis of relative expression of IL- $1 \beta$ among different groups showed that treatment with 5\% IL-Ra and $1 \%$ methylprednisolone significantly decreased the levels of IL-1 $\beta$ in the cornea compared to CsA $(P=0.02)$ and vehicle control $(P=0.003)$ treated groups (Fig 3$)$.

\section{Inhibition of lymphatics ingrowth in dry eye cornea}

The normal human cornea is avascular and alymphatic, thus suppressing both the afferent (lymphatic) and efferent (vascular) arms of the immune cycle. ${ }^{25,26}$ The lymphatic system plays an essential role in generating immune-inflammatory responses by directing the antigen-bearing immunocytes (e.g. dendritic cells) from the periphery to the draining lymph nodes where the T cells are primed and expanded. ${ }^{27}$ Our data on corneal lymphatic ingrowth showed a significant increase in the lymphatic area (LA) in the dry eye corneas compared to normal corneas $(0.14 \pm 0.018$ vs. $0.01 \pm 0.002$, respectively; $P=0.02)($ Fig $4 \mathrm{~A})$. A significant decreased in the LA was observed only in 5\% IL-1Ra $(0.05 \pm 0.001)$ and $1 \%$ methylprednisolone $(0.06 \pm 0.006)$ treated groups compared to the vehicle treated group $(0.14 \pm 0.01 ; P<0.04)$. (Figure 4B).

\section{DISCUSSION}

In recent years, inflammation has been shown to be key in the pathogenesis and amplification of dry eye disease severity. ${ }^{15}$ Among the various treatment options, $0.05 \%$ CsA has become one of the standard treatments for patients with moderate to severe DED in the United States; however CsA use is associated with tolerability issues such as stinging and burning in some patients. ${ }^{5,7}$ In addition to CsA, there are several studies that support the efficacy of topical corticosteroids in the treatment of keratoconjunctivitis sicca. ${ }^{4}$ However, the long-term use of topical corticosteroids is limited by numerous side effects including ocular hypertension, cataract, and corneal thinning. ${ }^{6}$ The current study demonstrates the beneficial effect of IL-1 blockade via the topical application of IL-1Ra in treating the ocular signs and reversing the inflammatory changes associated with dry eye at both the molecular and cellular levels. 
IL- $1 \alpha$ and IL-1 $\beta$ are both constitutively expressed by the corneal epithelium, and are potent mediators of corneal inflammation following their release in states of epithelial injury. ${ }^{28}$ Specifically, of relevance to DED, hyperosmolality stress is known to induce IL- $1 \beta$ expression in corneal epithelial cells. ${ }^{29} \mathrm{IL}-1$ has been implicated in inducing inflammatory cytokine and chemokine expression (including IL-6, monocyte chemotactic protein-1, and granulocyte stimulating factor), as well as matrix metalloproteinase synthesis by keratocytes. ${ }^{30}$ In accord with these findings, is the demonstration that levels of proinflammatory forms of IL-1 are directly correlated with the intensity of corneal fluorescein staining, ${ }^{13}$ and that IL-1 $\beta$ may contribute to the loss of corneal epithelial barrier function associated with ocular surface inflammation. ${ }^{31} \mathrm{We}$ show herein that IL-1Ra treated eyes had a significant reversal in corneal epithelial damage, indicated by decreased fluorescein staining, as compared with the untreated and vehicle groups.

The therapeutic efficacy of IL-1Ra is further supported by decreased corneal infiltration of $\mathrm{CD} 11 \mathrm{~b}+$ cells (which are rich sources of IL- $1 \beta^{32}$ observed in mice treated with IL-1Ra. While macrophages are known to reside in the corneal stroma, ${ }^{33}$ our laboratory has also previously shown infiltration by mature major histocompatibility complex class IIexpressing antigen-presenting cells in DED. ${ }^{24}$ IL-1 is indeed known to mobilize corneal APC infiltration ${ }^{34}$, likely via CC chemokine receptor expression by the APC. ${ }^{35}$ These observations are consistent with reported findings by Stapleton et al., showing reduced $\mathrm{CD} 11 \mathrm{~b}+$ influx into the corneal stroma following the topical application of IL-1Ra in a mouse model of corneal epithelial scrape injury. ${ }^{36}$ Thus, the blockade of IL-1, also suppressed corneal inflammation by subverting APC infiltration. These changes are important in disease pathogenesis and severity since the corneal APC mobilization is known to have a significant effect on the degree and rapidity of corneal immune responses, including graft rejection and herpes keratitis. ${ }^{37}$

Desiccating stress in DED initiates an immuno-inflammatory response that is sustained by the ongoing interplay between the ocular surface and various pathogenic immune cells, primarily of the CD4+ T compartment. ${ }^{38}$ Evidence suggests that the induction of pathogenic, autoreactive $\mathrm{T}$ cells primarily occurs in the regional lymph nodes of DED mice. ${ }^{39}$ Recently, Goyal et al. demonstrated that there is an ingrowth of lymphatic vessels in dry eye corneas ${ }^{17,18}$ which serve as potential conduits for the migration antigen presenting cells from ocular surface to draining lymph nodes where these cells prime naïve $\mathrm{T}$ cells to yet unknown ocular surface autoantigen(s). In the present study, we noticed that dry eye corneas treated with IL-1Ra showed a significant decrease in lymphatic growth. Downregulation of IL- $1 \beta$ could reduce the lymphangiogenesis in the mouse cornea through diminished production of potent pro-lymphangiogenic factors, vascular endothelial growth factor (VEGF)-C and VEGF-D. ${ }^{40}$ In addition, decreased macrophage infiltration in response to low levels of IL-1 on ocular surface could reduce corneal lymphangiogenesis. Previously, It has been shown that macrophages play a crucial role in corneal inflammatory lymphangiogenesis by potentially serving as precursor cells for de novo formation of lymphatic vessels. ${ }^{41,} 42$

We and other groups have recently identified IL-17 producing T helper cells (Th17) as dominant effectors capable of disrupting the corneal epithelial barrier in DED. ${ }^{43}, 44$ Furthermore, these Th17 cells are dysfunctional in that they are more resistant to suppression by T regulatory cells. ${ }^{45}$ Since IL-1 is known to potentiate the differentiation and survival of Th17 cells by synergizing with IL- 6 and IL- 23 46, 47 , we suggest that treatment with IL-1Ra may also act by suppressing Th17 activity at the ocular surface through inhibiting the effect of IL-1 on the survival of Th17 cells. 
In conclusion, our study shows the therapeutic effects of topical IL-1Ra in the amelioration of the clinical signs and the underlying inflammatory changes seen in dry eyes, comparable to that seen with topical methylprednisolone. These data suggest that the use of topical IL-1Ra could hold promise as a therapeutic modality for dry eyes disease and possibly in other inflammatory conditions of the cornea and ocular surface.

\section{Acknowledgments}

Funding/Support:

This work was supported by funding from the NIH (Grant: NIH/EY20889)

The authors thank sincerely Dr. Qiang Zhang and Nambi Nallasamy, Schepens Eye Research Institute, Boston for assisting in immunohistochemical and morphometric experiments.

\section{References}

1. The definition and classification of dry eye disease: report of the Definition and Classification Subcommittee of the International Dry Eye WorkShop (2007). Ocul Surf. 2007; 5(2):75-92. [PubMed: 17508116]

2. Miljanovic B, Dana R, Sullivan DA, Schaumberg DA. Impact of dry eye syndrome on vision-related quality of life. Am J Ophthalmol. 2007; 143(3):409-415. [PubMed: 17317388]

3. Pflugfelder SC. Antiinflammatory therapy for dry eye. Am J Ophthalmol. 2004; 137(2):337-342. [PubMed: 14962426]

4. Marsh P, Pflugfelder SC. Topical nonpreserved methylprednisolone therapy for keratoconjunctivitis sicca in Sjogren syndrome. Ophthalmology. 1999; 106(4):811-816. [PubMed: 10201607]

5. Brown MM, Brown GC, Brown HC, Peet J, Roth Z. Value-based medicine, comparative effectiveness, and cost-effectiveness analysis of topical cyclosporine for the treatment of dry eye syndrome. Arch Ophthalmol. 2009; 127(2):146-152. [PubMed: 19204231]

6. Carnahan MC, Goldstein DA. Ocular complications of topical, peri-ocular, and systemic corticosteroids. Curr Opin Ophthalmol. 2000; 11(6):478-483. [PubMed: 11141645]

7. Sall K, Stevenson OD, Mundorf TK, Reis BL. Two multicenter, randomized studies of the efficacy and safety of cyclosporine ophthalmic emulsion in moderate to severe dry eye disease. CsA Phase 3 Study Group. Ophthalmology. 2000; 107(4):631-639. [PubMed: 10768324]

8. Gabay C, Porter B, Fantuzzi G, Arend WP. Mouse IL-1 receptor antagonist isoforms: complementary DNA cloning and protein expression of intracellular isoform and tissue distribution of secreted and intracellular IL-1 receptor antagonist in vivo. J Immunol. 1997; 159(12):5905-5913. [PubMed: 9550387]

9. Arend WP. Interleukin-1 receptor antagonist. Adv Immunol. 1993; 54:167-227. [PubMed: 8379462]

10. Bresnihan B, Cunnane G. Interleukin-1 receptor antagonist. Rheum Dis Clin North Am. 1998; 24(3):615-628. [PubMed: 9710890]

11. Moreland LW. The role of cytokines in rheumatoid arthritis: inhibition of cytokines in therapeutic trials. Drugs Today (Barc). 1999; 35(4-5):309-319. [PubMed: 12973435]

12. Fisher CJJ, Dhainaut JF, Opal SM, et al. Recombinant human interleukin 1 receptor antagonist in the treatment of patients with sepsis syndrome. Results from a randomized, double-blind, placebocontrolled trial. Phase III rhIL-1ra Sepsis Syndrome Study Group. JAMA. 1994; 271(23):18361843. [PubMed: 8196140]

13. Solomon A, Dursun D, Liu Z, Xie Y, Macri A, Pflugfelder SC. Pro- and anti-inflammatory forms of interleukin-1 in the tear fluid and conjunctiva of patients with dry-eye disease. Invest Ophthalmol Vis Sci. 2001; 42(10):2283-2292. [PubMed: 11527941]

14. Dinarello CA. Biologic basis for interleukin-1 in disease. Blood. 1996; 87(6):2095-2147. [PubMed: 8630372]

15. Stern ME, Pflugfelder SC. Inflammation in dry eye. Ocul Surf. 2004; 2(2):124-130. [PubMed: 17216083] 
16. Barabino S, Shen L, Chen L, Rashid S, Rolando M, Dana MR. The controlled-environment chamber: a new mouse model of dry eye. Invest Ophthalmol Vis Sci. 2005; 46(8):2766-2771. [PubMed: 16043849]

17. Goyal S, Chauhan SK, El Annan J, Nallasamy N, Zhang Q, Dana R. Evidence of corneal lymphangiogenesis in dry eye disease: a potential link to adaptive immunity? Arch Ophthalmol. 2010; 128(7):819-824. [PubMed: 20625040]

18. Goyal S, Chauhan SK, Dana R. Blockade of Prolymphangiogenic Vascular Endothelial Growth Factor C in Dry Eye Disease. Arch Ophthalmol. 2011 Forthcoming.

19. Barabino S, Rolando M, Chen L, Dana MR. Exposure to a dry environment induces strain-specific responses in mice. Exp Eye Res. 2007; 84(5):973-977. [PubMed: 17397831]

20. Barabino S, Chen W, Dana MR. Tear film and ocular surface tests in animal models of dry eye: uses and limitations. Exp Eye Res. 2004; 79(5):613-621. [PubMed: 15500820]

21. Maruyama K, Ii M, Cursiefen C, et al. Inflammation-induced lymphangiogenesis in the cornea arises from CD11b-positive macrophages. J Clin Invest. 2005; 115(9):2363-2372. [PubMed: 16138190]

22. Bock F, Onderka J, Hos D, Horn F, Martus P, Cursiefen C. Improved semiautomatic method for morphometry of angiogenesis and lymphangiogenesis in corneal flatmounts. Exp Eye Res. 2008; 87(5):462-470. [PubMed: 18789928]

23. Hamrah P, Zhang Q, Liu Y, Dana MR. Novel characterization of MHC class II-negative population of resident corneal Langerhans cell-type dendritic cells. Invest Ophthalmol Vis Sci. 2002; 43(3):639-646. [PubMed: 11867578]

24. Rashid S, Jin Y, Ecoiffier T, Barabino S, Schaumberg DA, Dana MR. Topical omega-3 and omega-6 fatty acids for treatment of dry eye. Arch Ophthalmol. 2008; 126(2):219-225. [PubMed: 18268213]

25. Cursiefen C, Chen L, Saint-Geniez M, et al. Nonvascular VEGF receptor 3 expression by corneal epithelium maintains avascularity and vision. Proc Natl Acad Sci U S A. 2006; 103(30):1140511410. [PubMed: 16849433]

26. Ambati BK, Nozaki M, Singh N, et al. Corneal avascularity is due to soluble VEGF receptor-1. Nature. 2006; 443(7114):993-997. [PubMed: 17051153]

27. Hommel M. On the dynamics of T-cell activation in lymph nodes. Immunol Cell Biol. 2004; 82(1): 62-66. [PubMed: 14984596]

28. Wilson SE, Mohan RR, Mohan RR, Ambrosio RJ, Hong J, Lee J. The corneal wound healing response: cytokine-mediated interaction of the epithelium, stroma, and inflammatory cells. Prog Retin Eye Res. 2001; 20(5):625-637. [PubMed: 11470453]

29. Chen M, Hu DN, Pan Z, Lu CW, Xue CY, Aass I. Curcumin protects against hyperosmoticityinduced IL-1beta elevation in human corneal epithelial cell via MAPK pathways. Exp Eye Res. 2010; 90(3):437-443. [PubMed: 20026325]

30. Wilson SE, Esposito A. Focus on molecules: interleukin-1: a master regulator of the corneal response to injury. Exp Eye Res. 2009; 89(2):124-125. [PubMed: 19254714]

31. Kimura K, Teranishi S, Nishida T. Interleukin-1beta-induced disruption of barrier function in cultured human corneal epithelial cells. Invest Ophthalmol Vis Sci. 2009; 50(2):597-603. [PubMed: 19171646]

32. Dinarello CA. A clinical perspective of IL-1 $\beta$ as the gatekeeper of inflammation. Eur J Immunol. 2011; 41(5):1203-1217. [PubMed: 21523780]

33. Hamrah P, Liu Y, Zhang Q, Dana MR. The corneal stroma is endowed with a significant number of resident dendritic cells. Invest Ophthalmol Vis Sci. 2003; 44(2):581-589. [PubMed: 12556386]

34. Yamada J, Dana MR, Zhu SN, Alard P, Streilein JW. Interleukin 1 receptor antagonist suppresses allosensitization in corneal transplantation. Arch Ophthalmol. 1998; 116(10):1351-1357. [PubMed: 9790635]

35. Yamagami S, Hamrah P, Miyamoto K, et al. CCR5 chemokine receptor mediates recruitment of MHC class II-positive Langerhans cells in the mouse corneal epithelium. Invest Ophthalmol Vis Sci. 2005; 46(4):1201-1207. [PubMed: 15790880] 
36. Stapleton WM, Chaurasia SS, Medeiros FW, Mohan RR, Sinha S, Wilson SE. Topical interleukin-1 receptor antagonist inhibits inflammatory cell infiltration into the cornea. Exp Eye Res. 2008; 86(5):753-757. [PubMed: 18346730]

37. Jager MJ, Bradley D, Atherton S, Streilein JW. Presence of Langerhans cells in the central cornea linked to the development of ocular herpes in mice. Exp Eye Res. 1992; 54(6):835-841. [PubMed: 1325920]

38. Niederkorn JY, Stern ME, Pflugfelder SC, et al. Desiccating stress induces T cell-mediated Sjogren's Syndrome-like lacrimal keratoconjunctivitis. J Immunol. 2006; 176(7):3950-3957. [PubMed: 16547229]

39. El Annan JCSK, Ecoiffier T, Zhang Q, Saban DR, Dana R. Characterization of effector T cells in dry eye disease. Invest Ophthalmol Vis Sci. 2009; 50(8):3802-3807. [PubMed: 19339740]

40. Watari K, Nakao S, Fotovati A, et al. Role of macrophages in inflammatory lymphangiogenesis: Enhanced production of vascular endothelial growth factor C and D through NF-KappaB activation. Biochem Biophys Res Commun. 2008; 377(3):826-831. [PubMed: 18951870]

41. Xu H, Chen M, Reid DM, Forrester JV. LYVE-1-positive macrophages are present in normal murine eyes. Invest Ophthalmol Vis Sci. 2007; 48(5):2162-2171. [PubMed: 17460275]

42. Kerjaschki D. The crucial role of macrophages in lymphangiogenesis. J Clin Invest. 2005; 115(9): 2316-2319. [PubMed: 16138185]

43. Chauhan SK, Dana R. Role of Th17 cells in the immunopathogenesis of dry eye disease. Mucosal Immunol. 2009; 2(4):375-376. [PubMed: 19532120]

44. De Paiva CS, Chotikavanich S, Pangelinan SB, et al. IL-17 disrupts corneal barrier following desiccating stress. Mucosal Immunol. 2009; 2(3):243-253. [PubMed: 19242409]

45. Chauhan SK, El Annan J, Ecoiffier T, et al. Autoimmunity in dry eye is due to resistance of Th17 to Treg suppression. J Immunol. 2009; 182(3):1247-1252. [PubMed: 19155469]

46. Littman DR, Rudensky AY. Th17 and regulatory T cells in mediating and restraining inflammation. Cell. 2010; 140(6):845-858. [PubMed: 20303875]

47. Peck A, Mellins ED. Plasticity of T-cell phenotype and function: the T helper type 17 example. Immunology. 2010; 129(2):147-153. [PubMed: 19922424] 

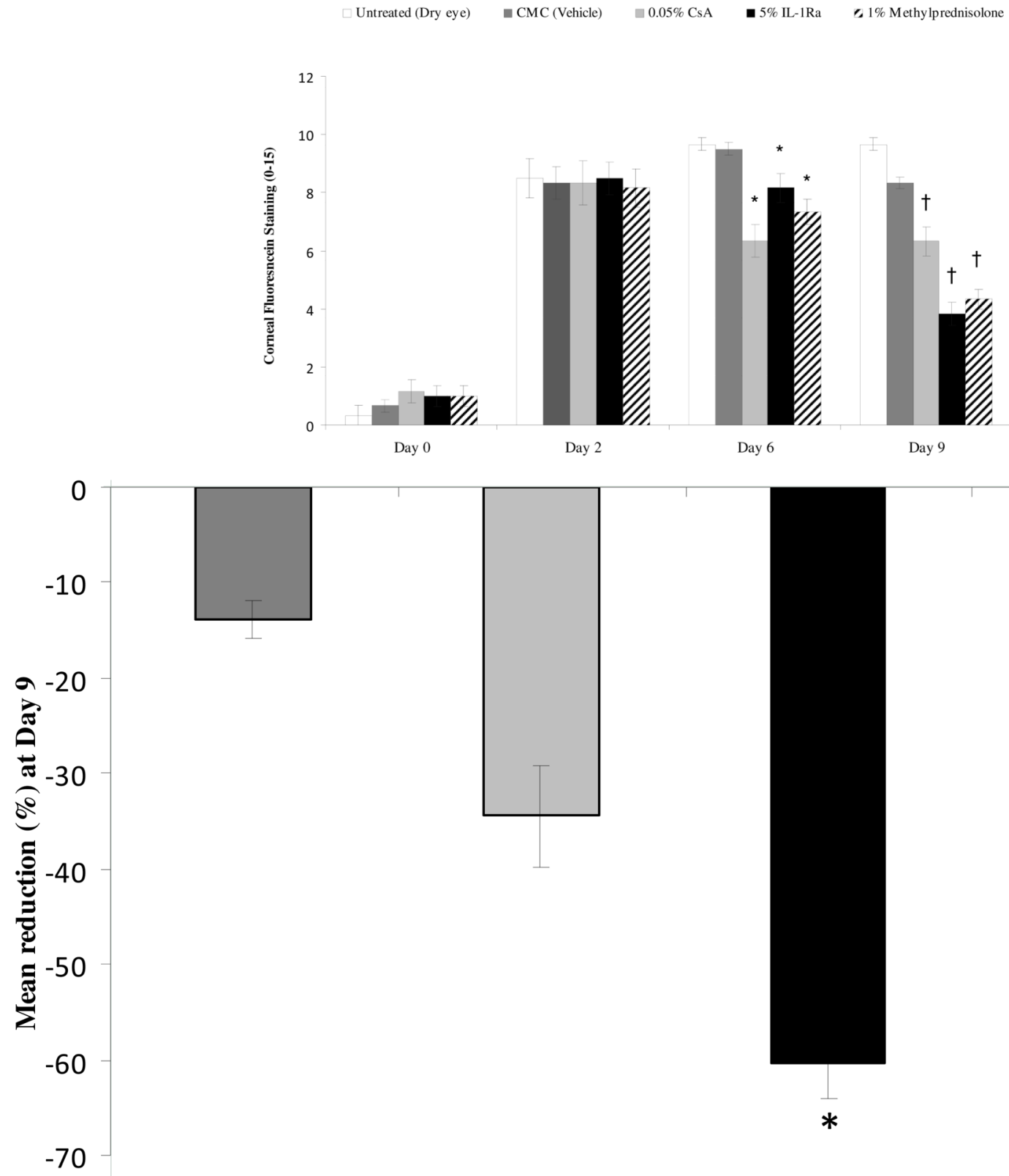

CMC (Vehicle)

$0.05 \% \mathrm{CsA}$

$5 \%$ IL-1Ra

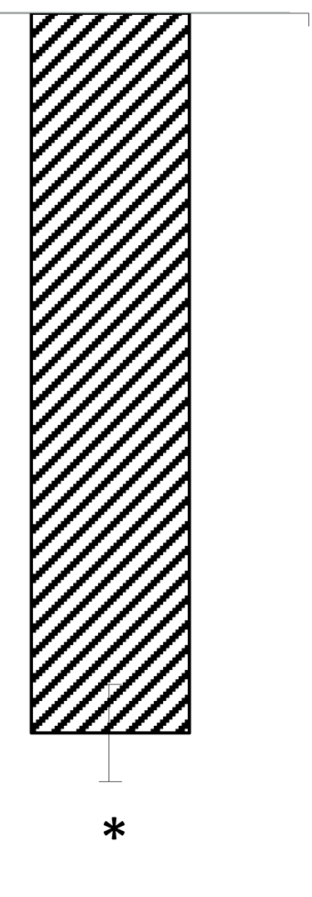

$1 \%$

Methylprednisolone

Figure 1.

Topical IL-1Ra effectively reduced corneal fluorescein staining scores in dry eye disease. (Top) Topical 5\% IL-1Ra, 1\% methylprednisolone and 0.05\% CsA treatment produced a significant decrease in corneal fluorescein staining compared to the CMC (vehicle) treated group at day $6(* P<0.01)$ and day $9(\dagger P<0.003)$. (Bottom) Mean reduction of corneal fluorescein staining scores compared to untreated (dry eye) group at day 9 showed that $5 \%$ IL-1Ra and 1\% methylprednisolone led to a statistically significant greater reduction in fluorescein staining compared to $0.05 \%$ CsA. Data are presented as mean \pm SEM. $(* P<$ $0.01)$. 


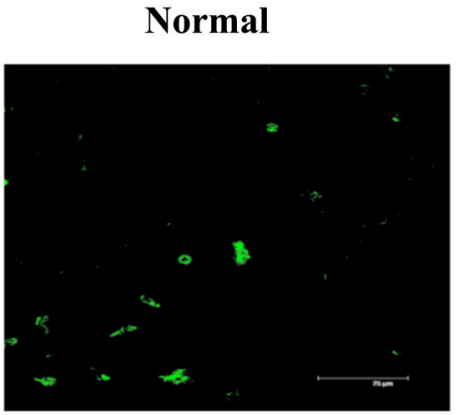

$0.05 \%$ CSA

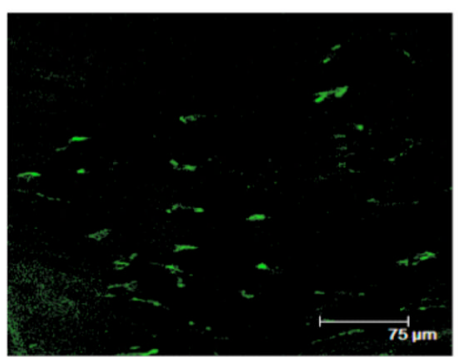

300

250

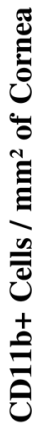

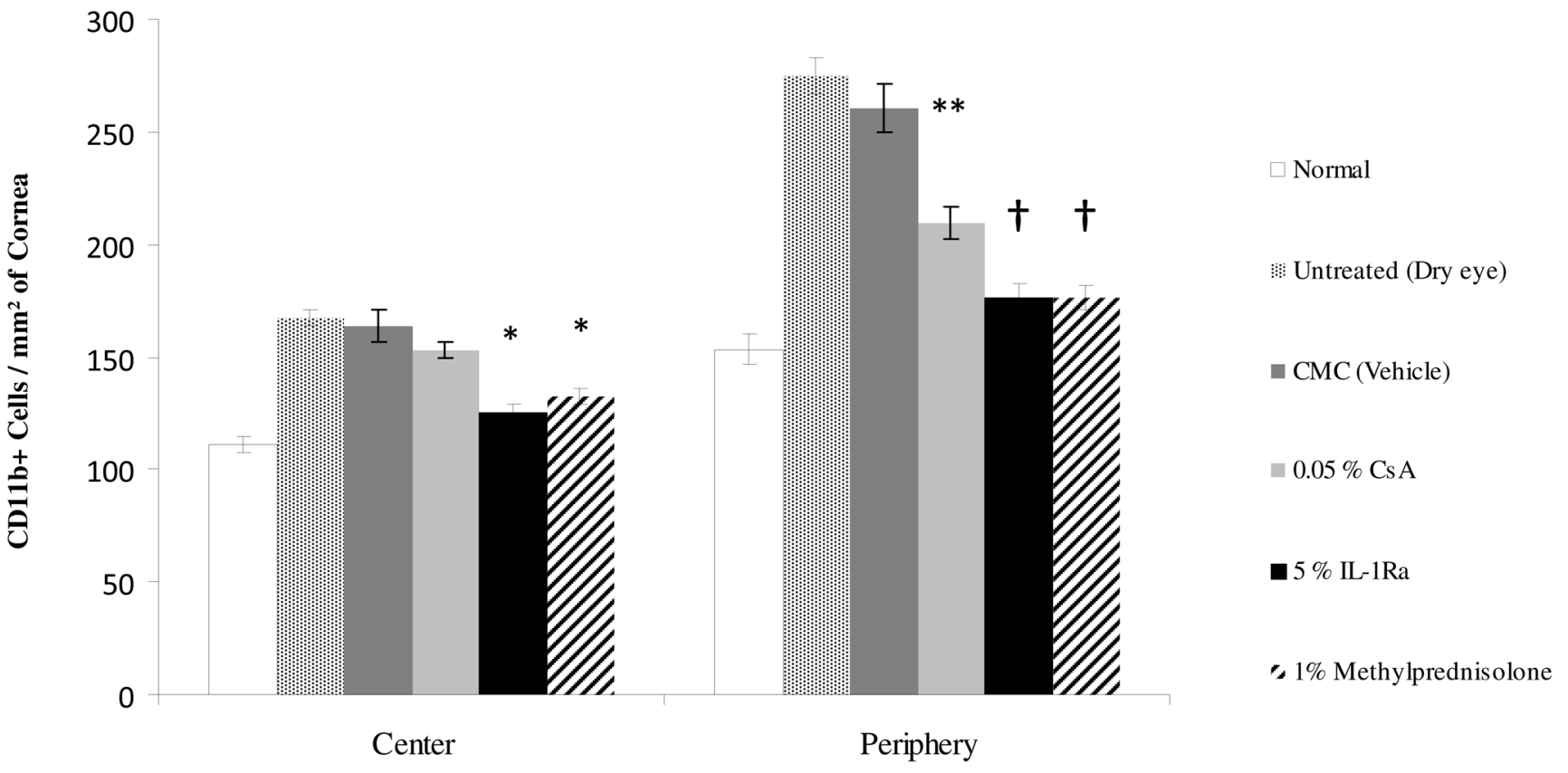

Figure 2.

Treatment with IL-1Ra and methylprednisolone significantly decreased the number of corneal CD11 $\mathrm{b}^{+}$cells in Dry Eye Disease. (Top) Representative confocal images of the whole-mount corneas. (Bottom) Eyes treated with 5\% IL-1Ra and 1\% methylprednisolone showed significantly decreased numbers of CD11 $\mathrm{b}^{+}$cells in the periphery and center of the cornea. * Indicates $P<0.05$ and $\dagger$ indicates $P<0.0001$ compared to the vehicle treated group. Topical $0.05 \%$ CsA significantly decreased the number of CD11b+ cells only in the periphery. ** Indicates $P<0.01$ compared to the vehicle treated group. Data are presented as mean $\pm \mathrm{SEM}$. 


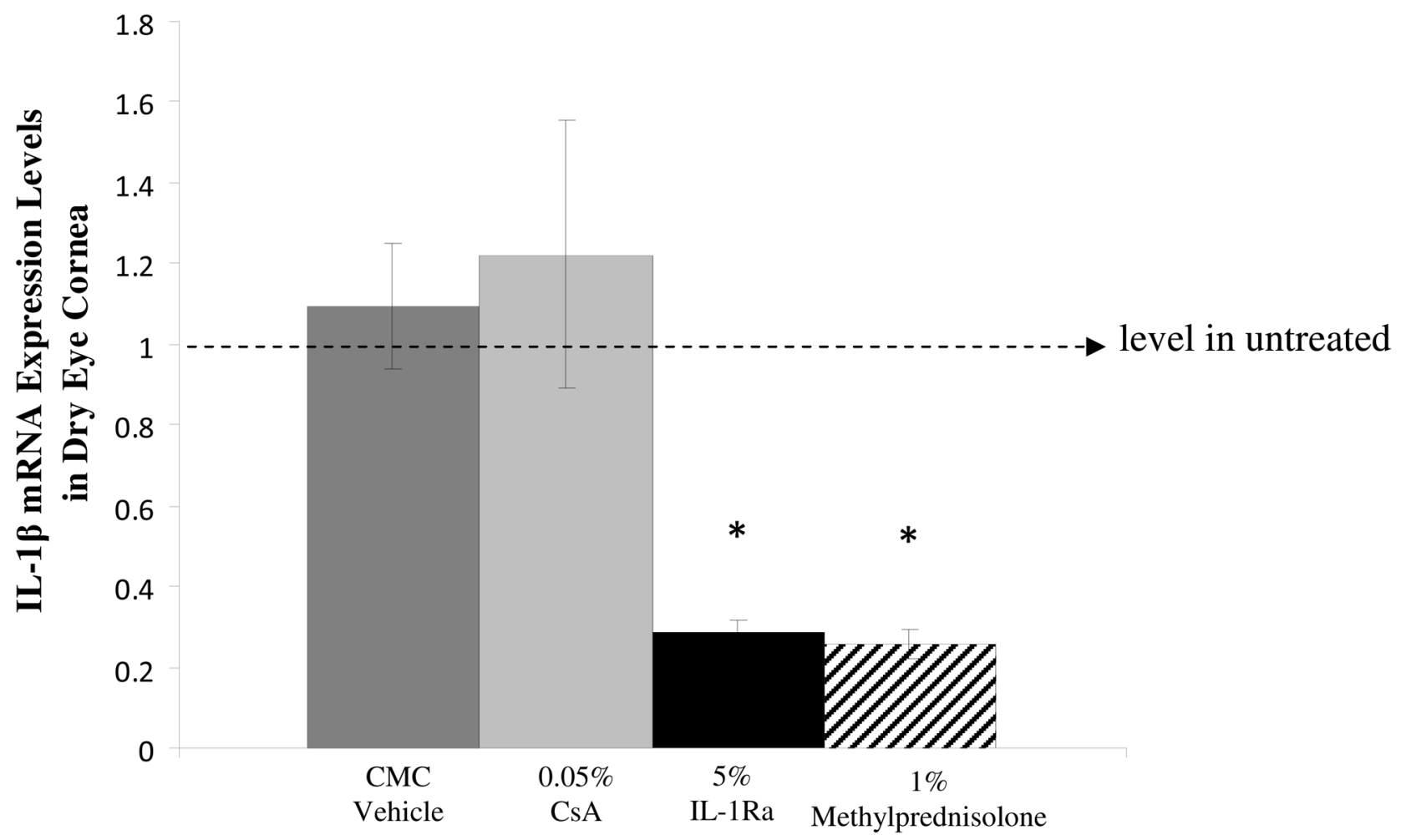

Figure 3.

Real-time polymerase chain reaction results showing that treatment with IL-1Ra and methylprednisolone significantly decreased the relative expression of IL-1 $\beta$ transcript in dry eye cornea. * indicates $P=0.003$ compared to CMC (vehicle). The horizontal line represents results normalized to messenger RNA expression levels in the corneas of the untreated dry eye group. Data are presented as mean \pm SEM. 

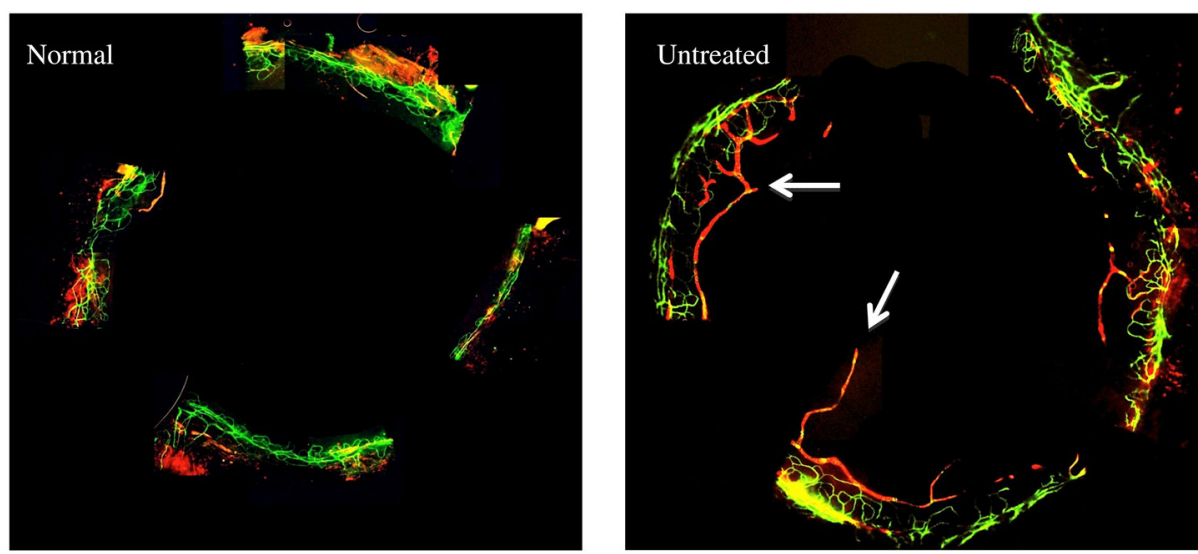

Lymphatic Area

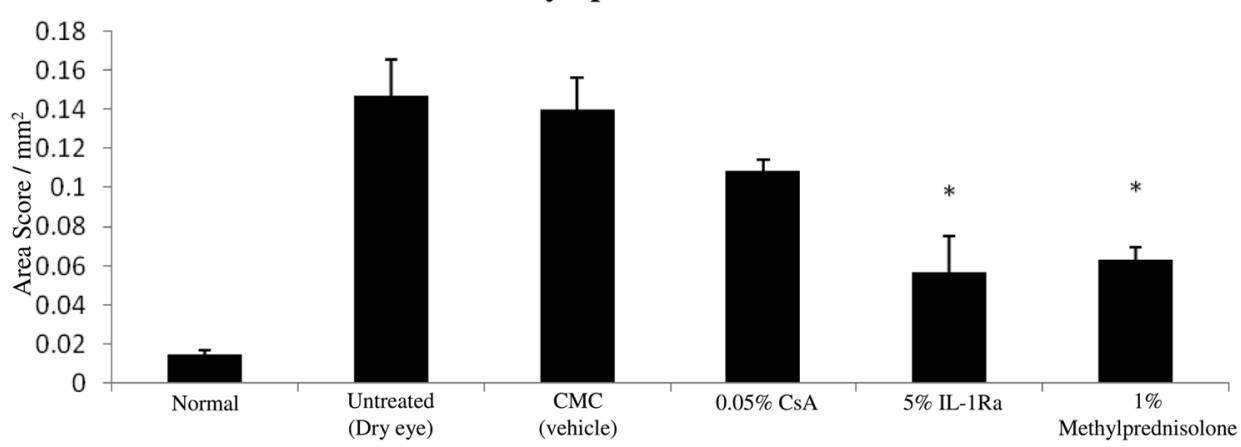

Figure 4.

Topical IL-1Ra reduced the ingrowth of lymphatics in dry eye cornea. (Top) Representative micrographs of cornea whole mounts stained with CD31 (Green) / LYVE-1 (Red). Arrows are pointing toward the ingrowth of lymphatics in the dry eye cornea. (Bottom) Treatment with IL-1Ra and methylprednisolone effective decreased the Lymphatic Area. $*$ indicates $P$ $<0.05$ compared to vehicle treated group. Data are presented as mean \pm SEM. 